http://jmscr.igmpublication.org/home/ ISSN (e)-2347-176x ISSN (p) 2455-0450

crossref DOI: https://dx.doi.org/10.18535/jmscr/v8i1.134

Journal Of Medical Science And Clinical Research

\title{
Study of Maternal Risk Factors in Small for Gestational Age (SGA) Babies with Fetal Malnutrition
}

Authors

\section{Dr Bapu Yelam M.D ${ }^{1 *}$, Dr Saira Merchant M.D. ${ }^{2}$, Mrs. Jiji Yelam M.Sc.(Nursing) ${ }^{3}$, Dr Abhishek Madhura M.D ${ }^{4}$, Dr Harshavardhan Khandait, MBBS $^{5}$}

${ }^{1}$ Assistant Professor, Dept of Paediatrics, Govt Medical College, Nagpur, Maharashtra, India 440003

${ }^{2}$ Professor, Dept of Paediatrics, Govt medical college, Nagpur, Maharashtra, India 440003

${ }^{3}$ Tutor, Kuwar Tilak Singh General Hospital, Nursing College, Gondia, Maharashtra, India

${ }^{4}$ Assistant Professor, Dept of Paediatrics, Govt Medical College, Nagpur, Maharashtra, India 440003

${ }^{5}$ Intern, Govt. Medical College, Nagpur, Maharashtra, India

*Corresponding Author

Dr Bapu Yelam

Assistant Professor, Dept of Paediatrics, Govt Medical College, Nagpur, Maharashtra, India 440003

Abstract
Introduction: Maternal risk factors for fetal malnutrition (FM) included adverse age, primiparity, low
pre-pregnancy weight and height, a bad obstetric history and pregnancy induced hypertension.
Malnutrition in the newborn might be missed if intrauterine growth curves only are used for assessment.
The CAN Score is a simple and rapid clinical scoring system for diagnosing fetal malnutrition in Small
for Gestational Age (SGA) babies.
Aim: The aim of the study is to assess association of high risk factors in mother like anemia, malnutrition
low BMI, pre-eclampsia, multiple pregnancy, maternal age (<18yrs), maternal weight (<40kg) and
height, socioeconomic status and prevalence of FM in SGA babies.
Subjects and Methods: This is a prospective hospital based study carried out at the Neonatology unit of
Tertiary Care Institute in Government Medical College, Nagpur. Baby-Mother pairs who met the
inclusion criteria for the study were recruited consecutively. Relevant biodata is recorded and babies
nutritional status were assessed using the Clinical Assessment of Nutritional Status Score chart. Data
were entered into a Microsoft Excel sheet and analyzed using standard statistical tools.
Results: In present study 903 term SGA neonates and mothers, $477(52.8 \%)$ (weight 2.5 kg) were males
and $426(47.2 \%)$ were females. The prevalence of FM in SGA babies is 34.21\%. Analysis of maternal risk
factors showed maternal age <18 yrs and $>30$ yrs, BMI <18, Anemia and PIH were associated with high
occurrence of FM and statistically significant (P<0.006).
Conclusion: The prevalence of FM is high in high risk mothers and highlights the need for evolving
appropriate interventions and strategies for its Prevention. Screening Programmes to identify the high
risk mothers in early pregnancy so that medical and nutritional interventions can be started early to
overcome the damaging effects of these risk factors. These interventions will have great long term impact
on improving child survival.
Keywords: Fetal malnutrition, prevalence, risk factors.




\section{Introduction}

The nutrition of women before conception, during pregnancy and lactation has profound effects on reproductive outcome and infant development. Thus, nutrition before conception is not only related to fertility but, in fact can affect early embryogenesis and lactation clearly affects fetal growth and infant development. Low birth weight is a consequence of being born too small or too early. Babies born small for gestational age (SGA) are at increased risk of death and developmental and behavioural problems in childhood ${ }^{[1]}$. These infants are increased risk of noninsulin dependent diabetes mellitus and cardiovascular disease in adult life. ${ }^{[2]}$ The causes of SGA are not well established ${ }^{[3]}$. Low birth weight is associated with lower socioeconomic status. ${ }^{[4]}$ The evidence accumulated over the past two decades indicates that being of small size at birth or malnourished during infancy, especially when followed by rapid weight gain during recovery, carries an increased risk for the development of chronic diseases in adulthood. These associations further extend the offspring to life-long health and support the socalled 'fetal origins of adult disease' or 'thrifty phenotype' hypothesis. Thus, the susceptibility to develop chronic diseases such as coronary heart disease, type- 2 diabetes mellitus, and hypertension can be the consequence of intrauterine adaptations to fetal under nutrition. These adaptations are thought to persist during adult life and become detrimental. Maternal risk factors for FM included adverse age, primiparity, low pre-pregnancy weight and height, a bad obstetric history and pregnancy-induced hypertension.

Purpose of this prospective Cohort Study is to assess association of high risk factors in mother like Anemia, Malnutrition, Preeclampsia, Multiple pregnancy, Maternal age, Maternal weight \& Height, Socioeconomic Status and Education etc and also to know prevalence of fetal malnutrition in full term SGA babies. Fetal malnutrition (FM) is a risk factor for increased neonatal morbidities and mortalities worldwide. Clinicians challenge is to identify SGA babies whose health is endangered in utero because of a hostile intrauterine environment and to monitor and intervene appropriately ${ }^{[5]}$. Assessment of nutritional status of fetus has been a major concern to many clinicians because of the potentially serious sequelae of malnutrition on multiple organ systems ${ }^{[6,7]}$. Fetal biometry has been used to identify malnourished fetuses as early as possible. Perinatal problems and or long term central nervous system sequelae are known to occur primarily in babies with fetal malnutrition (FM) whether appropriate for gestational age (AGA) or SGA but less so among those who are SGA but without fetal malnutrition ${ }^{[8]}$. There is a need for prompt identification of babies with FM. Features of malnutrition must therefore be sought for, and appropriately diagnosed and treated in every baby at risk. The anticipatory management of such infants at birth may decrease morbidity and improve the survival of such infants ${ }^{[8,9,10]]}$. Study enrolled 903 term SGA neonates and mothers, CAN Score is applied for babies.

Prevalance of fetal malnutrition in present study is $34.21 \%$ in term SGA babies. All anthropometric parameters like birth weight, length, head circumference and ponderal index are significantly low in SGA babies with fetal malnutrition as compared to SGA babies without FM. "Fetal malnutrition", is a term coined by Scott and Usher ${ }^{[10]}$, defined as failure to acquire adequate quantum of fat and muscle mass during intrauterine growth ${ }^{[8,9]}$. In severe $\mathrm{FM}$, the neonate may look "emaciated" or "marasmic" as the skin appears "several sizes" too large for the baby. Fetal growth retardation is a risk factor for postnatal growth retardation, cardiovascular and metabolic problems later on in life and adverse neurodevelopmental outcome. Malnutrition in the newborn might be missed if intrauterine growth curves only are used for assessment.

\section{Material and Methods}

The present prospective observational study was conducted in the Neonatology unit of Tertiary care Institute at Government Medical College Nagpur, 
of central India. The study group consisted of 903 mothers and 903 term SGA (wt. $<2.5 \mathrm{~kg}$ ) neonates of gestational age >37 weeks born with NVD/LSCS. Babies with major congenital malformations, premature babies ( $<37$ weeks of GA) and weight $>2.5 \mathrm{~kg}$ were excluded. After obtaining written informed consent from parents, clinical assessment of nutrition and anthropometric evaluation were carried out between 24 to $48 \mathrm{hr}$ of birth in all neonates, so Sample size required for study was 844 . Hence 903 newborn and mothers were included in the study ${ }^{[11]}$. A pretested, semi-structured questionnaire was used; this comprised by detailed information related to personal biodata, obstetric history, complaints of presenting pregnancy, h/o labour, delivery, and available health care facility, height, weight, systemic and obstetric examination and result of investigations were obtained from mother's case record. Following risk factors were considered and included in the study: Anemia ( $\mathrm{Hb}<10 \mathrm{gm} \%)$, Mother's with a weight on less than $40 \mathrm{~kg}$, height $<145 \mathrm{~cm}$, Pre-eclampsia and eclampsia, Elderly primi (30 years or above), Twins, Hydroamnios, Elderly grandmultipara, Pregnancy associated with systemic disease ( Cardiovascular disease, Kidney disease, Diabetes, etc, Tobacco use and Frequent pregnancies. Chronic hypertension was taken as systolic blood pressure of at least140 $\mathrm{mmHg}$ and a diastolic of at least $90 \mathrm{mmHg}$ before and after 20 weeks GA $^{[12]}$ Preeclampsia, on the other hand, was taken as raised blood pressure (at least 140/90 mmHg) after 20 weeks GA taken twice, $6 \mathrm{~h}$ apart in a pregnant woman in addition to pedal edema and protienuria ${ }^{[13,14]}$. Mothers were weighed within $24 \mathrm{~h}$ of delivery, and their heights were measured using a non stretchable meter rule. Body mass indices (BMIs) were calculated using the formula: $\mathrm{BMI}=$ weight (in $\mathrm{kg}$ )/height ${ }^{2}$ (in meters)[15] and interpreted as follows: underweight $=<18.5 \mathrm{~kg} / \mathrm{m}^{2}$, normal weight $=18.5-24.9 \mathrm{~kg} / \mathrm{m}^{2}$, overweight $=25-29.9$ $\mathrm{kg} / \mathrm{m}^{2}$, and obesity as $30 \mathrm{~kg} / \mathrm{m}^{2}$ and above. ${ }^{[15]}$ Institutional ethical clearance obtained for the study. The hypothesis of this study was that nutritional status of term SGA babies is more important prognostically than its birth weight. The prevalence of FM is high in high risk mothers and highlights the need for evolving appropriate interventions and strategies for its prevention.

\section{Statistical Analysis}

Demographic, Anthropometric and clinical parameters were presented as mean \pm SD. Categorical variables were expressed in actual numbers and percentages. Unpaired t-test was performed to compare mean birth weight, Ponderal index (PI), Length, and Head circumference (HC) between well nourished and fetal malnutrition groups. Categorical variables are compared by Chi square statistics. Analysis of maternal risk factors showed maternal age $<18$ yrs and $>30$ yrs, BMI <18, Anemia and PIH were associated with high occurrence of FM and statistically significant $(\mathrm{P}<0.006)$. All tests were 2 sided. Statistical software STATA version 10.0 was used for Statistical analysis.

\section{Results}

In present study 903 term SGA neonates $477(52.8 \%) \quad$ (wt $<2.5 \mathrm{~kg}$ ) were males and $426(47.2 \%)$ were females. Of all these term SGA babies, 309 (34.21\%) were detected to have Fetal malnutrition based on CAN Score of $<25$. Thus prevalence of fetal malnutrition in SGA babies is $34.21 \%$.

Table 1: Anthropometric characteristic of SGA population by CAN score

\begin{tabular}{|lccc|}
\hline & \multicolumn{2}{c|}{ CAN Score } & \multirow{2}{*}{ p.value } \\
\cline { 2 - 3 } & $<25$ SGA (FM) & 2 25 SGA & $0.000, \mathrm{HS}$ \\
\hline Birth weight $(\mathrm{kg})$ & $1.82 \pm 0.35$ & $2.07 \pm 0.27$ & $0.4175, \mathrm{NS}$ \\
\hline Length $(\mathrm{cm})$ & $47.04 \pm 1.01$ & $47.09 \pm 0.66$ & $0.000, \mathrm{HS}$ \\
\hline Head circumference $(\mathrm{cm})$ & $32.14 \pm 0.84$ & $32.61 \pm 0.62$ & $0.000, \mathrm{HS}$ \\
\hline Ponderal Index & $1.89 \pm 0.31$ & $2.12 \pm 0.22$ & \\
\hline
\end{tabular}


Table 1 Shows that all anthropometric parameters are significantly low in malnourished term SGA babies except length

Table 2: Comparison of Anthropometric indicators of growth using CAN score

\begin{tabular}{|lrrrr|}
\hline \begin{tabular}{l} 
Birth $\begin{array}{l}\text { weight } \\
\text { (kg) }\end{array}$ \\
\cline { 2 - 3 }
\end{tabular} & $\begin{array}{r}\text { CAN(309) } \\
\text { SGA (FM) }\end{array}$ & $\begin{array}{r}\mathbf{2 5 ( 5 9 4 )} \\
\text { SGA }\end{array}$ & Chi square & p.value \\
\hline$<1.5(55)$ & $51(92.72 \%)$ & $04(7.2 \%)$ & 89.06 & $0.000, \mathrm{HS}$ \\
\hline $1.5-2.0(455)$ & $172(37.80)$ & $283(62.19)$ & 5.23 & $0.0225, \mathrm{~S}$ \\
\hline $2.0-2.5(393)$ & $86(21.88)$ & $307(78.11 \%)$ & 47.68 & $0.000 \mathrm{HS}$ \\
\hline
\end{tabular}

Table 2 Shows there is a significantly higher occurrence of fetal malnutrition (p-value <0.05) in term SGA babies with birth weight $<1.5 \mathrm{~kg}$

Table No.3: Maternal age with SGA with or without FM

\begin{tabular}{|l|c|c|c|c|}
\hline $\begin{array}{l}\text { Age of mothers (in } \\
\text { yrs) }\end{array}$ & $\begin{array}{c}<25(\mathbf{3 0 9}) \\
\text { Malnourished }\end{array}$ & $\begin{array}{c}\mathbf{2 5} \text { (594) Well } \\
\text { nourished }\end{array}$ & Chi square & p.value \\
\hline$<18(03)$ & $03(1 \%)$ & 0 & 5.78 & $0.040, \mathrm{~S}$ \\
\hline $18-20(241)$ & $96(31.06 \%)$ & $145(24.41 \%)$ & 0.02 & $0.032, \mathrm{~S}$ \\
\hline $21-23(297)$ & $93(30.09 \%)$ & $204(34.34 \%)$ & 37.99 & $0.198, \mathrm{NS}$ \\
\hline $24-27(244)$ & $77(24.91 \%)$ & $167(28.11 \%)$ & 0.147 & $0.305, \mathrm{NS}$ \\
\hline $28-30(81)$ & $21(6.79 \%)$ & $60(10.10 \%)$ & 0.182 & $0.085, \mathrm{NS}$ \\
\hline$>30(37)$ & $19(6.14 \%)$ & $18(3.03 \%)$ & 22.12 & $0.023, \mathrm{~S}$ \\
\hline Mean age & $23.15 \pm 3.91$ & $22.80 \pm 2.98$ & & \\
\hline
\end{tabular}

Table 3 shows that the age of mothers $<20$ yrs and $>30$ yrs is significant to p.value (0.040) is a high risk factor in mothers for FM .

Table No.4: BMI with SGA with or without FMs

\begin{tabular}{|l|c|c|c|c|}
\hline BMI in $\mathbf{~ k g} / \mathbf{m}^{\mathbf{2}}$ & $\begin{array}{c}<\mathbf{2 5 ( 3 0 9 )} \\
\text { Mal nourished }\end{array}$ & $\begin{array}{c}\mathbf{2} \text { 25 (594) } \\
\text { Well nourished }\end{array}$ & Chi square & P value \\
\hline$<18(214)$ & $90(29.12 \%)$ & $124(20.87 \%)$ & 7.65 & $0.006, \mathrm{HS}$ \\
\hline $18-24.99(638)$ & $211(68.28 \%)$ & $427(71.88 \%)$ & 1.27 & $0.260, \mathrm{NS}$ \\
\hline $25-28.99(51)$ & $8(2.58 \%)$ & $43(7.23 \%)$ & 8.24 & $0.004, \mathrm{HS}$ \\
\hline Mean BMI & $19.78 \pm 2.33$ & $20.39 \pm 2.54$ & & \\
\hline
\end{tabular}

Table 4 shows that when we taken BMI $<18$, there is more significant of p.value $(0.006 \mathrm{HS})$, is a one of high risk factor for FM.

Table 5: Parity with SGA with or without FM

\begin{tabular}{|l|c|c|c|c|}
\hline Parity & $\begin{array}{c}<\mathbf{2 5} \\
\text { Mal nourished }\end{array}$ & $\begin{array}{c}\mathbf{2} \text { 25 } \\
\text { Well nourished }\end{array}$ & Chi square & p.value \\
\hline Primi (624) & $205(32.85 \%)$ & $419(67.14 \%)$ & 2.38 & 0.195, NS \\
\hline P2 (104) & $35(33.65 \%)$ & $69(66.34 \%)$ & 1.16 & $0.430, \mathrm{NS}$ \\
\hline P3 (175) & $69(39.42 \%)$ & $106(60.57 \%)$ & 1.16 & 0.076, NS \\
\hline
\end{tabular}

When parity was analyzed as a risk factor for fetal malnutrition, there was no significant statistical difference. It shows that parity was not a significant risk factor for fetal malnutrition in SGA babies

Table 6: Maternal disorders with SGA with or without FM

\begin{tabular}{|l|c|c|c|c|c|}
\hline $\begin{array}{l}\text { Risk factors in } \\
\text { mothers }\end{array}$ & $\begin{array}{c}<\mathbf{2 5}(\mathbf{3 0 9}) \\
\text { Mal nourished }\end{array}$ & $\begin{array}{c}\mathbf{2 5} \text { (594) } \\
\text { Well nourished }\end{array}$ & RR & 95 \% C.I. & p.value \\
\hline Anaemia (332) & $129(41.74 \%)$ & $203(34.17 \%)$ & 3.10 & $2.21-4.36$ & $0.000, \mathrm{HS}$ \\
\hline PIH (122) & $91(29.44 \%)$ & $31(5.21 \%)$ & 2.02 & $1.15-3.54$ & $0.0077, \mathrm{HS}$ \\
\hline UTI (11) & $05(1.61 \%)$ & $06(1.01 \%)$ & 1.61 & $0.49-5.20$ & $0.4294, \mathrm{NS}$ \\
\hline SCD (10) & $03(0.97 \%))$ & $07(1.17 \%)$ & 0.82 & $0.14-3.63$ & $0.7774, \mathrm{NS}$ \\
\hline Malaria (09) & $02(0.64 \%)$ & 07 & 0.54 & $0.05-2.88$ & $0.4458, \mathrm{NS}$ \\
\hline
\end{tabular}

Table 6 Shows that Anaemia and PIH is highly significant (P.value 0.000HS), as a high risk factor for FM. 
Table 7: Comparison of socio-economic status between well nourished and mal nourished SGA babies

\begin{tabular}{|c|c|c|c|}
\hline Socio-economic status & $\begin{array}{c}<25(309) \quad \text { Mal } \\
\text { nourished }\end{array}$ & $\begin{array}{c}\geq 25 \text { (594) Well } \\
\text { nourished }\end{array}$ & p.value \\
\hline Middle(244) & $88(36.06 \%)$ & $156(63.93 \%)$ & Chi square $=4.8230$ \\
\hline Lower (659) & $221(33.53 \%)$ & $438(66.46 \%)$ & $\mathrm{P}=0.185, \mathrm{NS}$ \\
\hline
\end{tabular}

Table 0 shows not very much significance as a high risk factor for FM.

\section{Discussion}

Not many studies reported maternal risk factors for fetal malnutrition in term SGA neonates. Few studies reported fetal malnutrition in preterm infants and its impact on neonatal outcome. Large number of studies have reported fetal malnutrition in term AGA babies. The aim of the study is to assess association of high risk factors in mother like Aneamia, malnutrition, preeclampsia, multiple pregnancy, maternal age, maternal weight and height and prevalence of FM in SGA babies. The study comprised of 903 term SGA babies, comprising of 309 (34.21\%) who had fetal malnutrition according to CAN Score and remaining 594 babies had no fetal malnutrition.

When maternal risk factors were taken into consideration for development of FM, it was found that young maternal age and low body mass index in mothers proved to be very significant risk factors for the development of FM (table $3 \& 4$ ). However, parity when taken into consideration did not prove to be statistically significant (table 5). The present study revealed that maternal anemia and PIH were significant risk factors for the development of fetal malnutrition. However, the other potential risk factors such as sickle cell disease, UTI and malaria did not prove to be statistically significant (table 6). The assessment of socio-economic status as a risk factor for FM did not reveal statistically significant results (table 7).

Study by Maternal factors such as primiparity, multi parity, age under 20yrs, age $>30 \mathrm{yrs}$ etc have been analyzed as risk factors for FM. Fetal malnutrition occurred in 13.5 percent newborn of primipara mother and in only 8.4 percent of babies of multipara mother. The incidence dropped in the second and third pregnancies. (to $6.9 \%)$ and then rose again with each successive pregnancy to $10.6 \%$ in the sixth and later pregnancies. (Scott and Usher-1). Scott and Usher ${ }^{[10]}$ found that there was a higher incidence of fetal malnutrition in unmarried mothers $(13.5 \%)$ and in mothers who were less than 20 years in age (13/5\%). Unmarried mothers and younger mothers, to be primiparous had babies with higher rates of prematurity. As proved before, they were associated with high incidence of fetal malnutrition. Fetal malnutrition did not occur more commonly in married and young mothers when primipara and multipara were considered separately. In the present study, there was higher incidence of FM in young mothers with age less than 20 years and in mother with age $>30$ yrs. (Table3). And maternal diseases in general did not result in a significantly higher incidence of fetal malnutrition.

The study by Scott and Usher ${ }^{[10]}$ does not lend support to any of the prevailing hypothesis concerning etiology in fetal malnutrition. Postmature infants were not more frequently malnourished. Elderly women did not have a higher incidence. Placental weight was normal is proportion to fetal weight. There was no correlation with socioeconomic status. Similarly in the present study, socio-economic status and parity did not prove to be statistically significant risk factors for FM when analyzed by CAN score.(table 7). Maternal disease and anemia did not play a role as risk factors in the study done by Scott and Usher ${ }^{[10]}$. Toxemia did not significantly increase the incidence, although severe toxemia might well have been found to do so if the study population had included more than 5 severe preeclampsia patients and no eclampsia patients ${ }^{6}$. However, in the present study, PIH and Maternal anemia did prove to be significant risk factors for FM. (table 6). The study done by Chin chu lin et 
$\mathrm{al}^{[16]}$ revealed 18 high risk factors that may be attributed to the development of fetal growth retardation in the study population. It was found that fetal malnutrition was prevalent in $80 \%$ of symmetric and $70 \%$ of asymmetric I. U. G. R in the study population. This data was consistent with Galbraith et al ${ }^{[17]}$, who found that two thirds of IUGR infants come from the population with risk factors. It is interesting to find that an almost equal incidence of symmetric and asymmetric IUGR infants were produced by pregnancies associated with such high risk factors as chronic hypertension, anaemia, antepartum hemorrhage, and twin gestations. Deodhar et $\mathbf{a l}^{[\mathbf{1 8 ]}}$ in their study reported maternal risk factors for fetal malnutrition as adverse age, primiparity, low prepregnancy weight and height, a bad obstetric history and pregnancy induced hypertension. Adebami OJ et $\mathbf{a l}^{[19]}$ recently reported an incidence of $18.8 \%$ of preterm newborns to have FM and significant risk factors for FM included lack of adequate antenatal care, young maternal age (<18yrs), primiparity, maternal undernutrition $\left(\mathrm{BMT}<18.5 \mathrm{~kg} / \mathrm{m}^{2}\right.$ and $\left.\mathrm{MAC}<23.5 \mathrm{~cm}\right)$, low socio economic status, pregnancy induced hypertension, antepartum hemorrhage and maternal infections especially malaria, urinary tract infections.

Prevalence of FM in Preterm neonates (40\%) was documented by B.N.Ezenwa ${ }^{[20]}$ and $48.9 \%$ as reported by Almarzoki et al ${ }^{[21]}$ from Iraq. It is however, higher than the $26.59 \%$ documented from India by Kamath et $\mathrm{al}^{[22]}$. Study by Adebami et $\mathrm{al}^{[19]}$ reported that, The mean weight, mid arm circumference, and Ponderal index of babies with FM were significantly lower than those of babies without FM $(\mathrm{p}<0.0001)$. Jarai et $\mathrm{al}^{[23]}$ investigated a mixed group of preterm, term, and post term SGA infants using different indices of body proportions and pointed to the significance of soft tissue wasting rather than low birth weight for diagnosis of FM. Mehta S, Tandon et $\mathrm{al}^{[24]}$ reported that, CAN score $<25$ separated $60 \%$ of the babies as well nourished and $40 \%$ as malnourished. Weight for age and Ponderal index classified $70-75 \%$ of babies as well nourished
(AGA) and 25-30\% as malnourished. Also $\mathrm{MAC} / \mathrm{HC}$ classified nearly half the babies as well nourished and half as malnourished. Deodhar et al $^{[18]}$ reported fetal malnutrition in $19.6 \%$ of all term neonates $(84.2 \%)$ of the SGA, $12.9 \%$ of AGA babies while Metcoff reported FM in $5.5 \%$ of AGA and $54 \%$ of SGA babies. Study by Preeti Waghmare et $\mathbf{a l}^{[25]}$ reported that CAN score identified overall $37.1 \%$ babies as malnourished and $84.8 \%$ of SGA babies were malnourished. Study by (Leeladhar ${ }^{[26]}$ reported FM in $8.3 \%$ of AGA 25/373 and (54.89\%) 112/187 SGA babies. Study by Naveen Sankhyan ${ }^{[8]}$ reported FM in $4 \%$ of AGA and $(57.1 \%)$ of SGA babies a overall occurrence of FM was $28 \%$ of all lnewborn. Study by Ayse Korkmaz ${ }^{[27]}$ reported that preterm infants with gestational age between 28-34 of total 93 preterm incidence of fetal malnutrition was $54.8 \%$ based on CAN score. The Study by Sankhyan et $\mathrm{al}^{[11]}$ reported, when CAN Score was compared to standard, weight for gestation and Mid arm circumference (MAC)/Head circumference (HC) had the highest sensitivity to identify malnourished neonates (92.5\% and 90.5\%).

\section{Conclusion}

The prevalence of FM is high in high risk mothers and highlights the need for evolving appropriate interventions and strategies for its prevention. Screening programmes to identify the high risk mothers in early pregnancy so that medical and nutritional interventions can be started early to overcome the damaging effects of these risk factors. These interventions will have great long term impact on improving child survival.

Funding: No funding sources

Conflict of interest: None declared.

Ethical approval: The study was approved by the Institutional Ethical Committee.

\section{References}

1. Allen MC. Developmental outcomes and follow up of small for gestational infants. Semin Perinatol 1984,8:123-56. 
2. Barker DJ, Gluckman PD, Godfrey KM, et al. Fetal nutrition and cardiovascular disease in adult life.Lancet1993;341:93841.

3. Kramer MS. Determinants of low birth weight: methodological assessment and metaanalysis.Bull WHO 1987;65:663-737.

4. Spencer N, Logan S.Social influences on birth weight. Arch Dis Child fetal Neonatal Ed2002;86:F6-7.

5. WHO Chronicle 32:200-201,1978.

6. Lockwood CJ and Weiner S. Assessment of fetal growth. Clin perinatol 13:235,1986 .

7. Georgieff MK and Sasanow SR. Nutritional assessment of the neonate. Clin Perinatol 13:72- 89, 1986

8. Metcoff J. Clinical assessment of nutritional status at birth. Fetal malnutrition and SGA are not synonymous. Pediatr Clin North Am 41:875-91,1994.

9. Jayant D and Rajkumar J. Study of the prevalence and high risk factors for fetal malnutritution in term newborn. Ann Trop Paediatr , 19:273-77,1999.

10. Scott KK and Usher RH. Fetal malnutrition: Its incidence causes and effects .Am J Obstet Gynaecol 94: 95163,1966.

11. Sankhyan N, Sharma VK, Singh S, Detection of fetal malnutrition using “CANSCORE". Indian J.Pediatr.76:903906,2009.

12. Onyiriuka, Okolo AA. Small for gestational age, ponderal index and neonatal polycythaemia: A study of their association with maternal hypertension among Nigerian womwn. Ann Afr Med 2005;4:154-9.

13. Roberts JM, Cooper DW. Pathogenesis and genetics of preeclampsia. Lancet 2001:357:53-6.(14).

14. Roberts JM, Redman CW. Preeclampsia: More than pregnancy-induced hypertension. Lancet

1993:341:144751.(15).

15. World -Health Organization. Obesity: Preventing and Managing the Global Epidemic. Report of a WHO Consultation on Obesity. Geneva: World Health Organization;1997.p.6(16).

16. Chin chu et al, Composition of associated high risk factors and perinatal outcome between symmetric and asymmetric fatal intrauterine growth retardation, Am J Obstet Gynecol June1991.

17. Galbraith et al, Altman DG, Hytten FE. Intrauterine growth retardation; lets be clear about it. $\mathrm{Br}$ J. Obstet Gynacol;96:1127,1989.

18. Deodhar J, Jarad R.Study of the prevalence of and high risk factors in the etiology of fetal malnutrition in Nigeria. Pediatr Int 49:150-155,2007.

19. Adebami OJ, Oyedeji GA, Owa. JA, Oyelami OA. Maternal factors in the etiology of fetal malnutrition in Nigeria. Pediatr Int.49:150-155,2007

20. B.N. Ezenwa, V.C. Ezeaka.Is canscore a good indicator of fetal malnutrition in preterm newborn. Alex J Med 2017.

21. Almarzoki JM, Rana DJ. Comparative study between clinical assessment of nutritional status score (CAN Score) and anthropometry in the assessment of fetal malnutrition. Int Res J Med Sci.2015,3(7):8-12.

22. Kamath MK, Raoss, Shenoy RD. Assessment of fetal malnutrition by body mass index and intrauterine growth curves :a comparative study. Int J Contemp Pediatr.10 may 2016

23. Jarai I.J. Mestyan K Schuktz A, Laxar M, Halasz I Krasy. Body size and neonatal hypoglycaemia in intrauterine growth retardation. Early Hum Dev1:25-38,1977.

24. Mehta S, Tendon A, Dua T, Kumari S, Singh SK. Clinical assessment of 
nutritional status at birth, Indian

Pediatr.35:423-428, 1998.

25. Preeti Waghmare et al: Assessment of fetal malnutrition by CAN

Score.Vol9,Jan2012.

26. Leeladhar et al. Detertion an fetal malnutrition by CAN Score at birth and its comparison with other methods in determining intrauterine growth. Pediatric infection disease Conference 2010.

27. Ayse A, Korknaz. Ozlem O Teksam, Murat M, Yurdakok, Sule S Yigit and Gulsevin G. Tekinalp Turk J.Pediatr 53(3);261-8,201. 